\title{
Living Kidney Donation-Subjective Experiences of Donors before and Two Years after Donation
}

\author{
Michael Langenbach ${ }^{1}$, Andrea Stippel ${ }^{2}$, Dirk Stippel ${ }^{3}$ \\ ${ }^{1}$ Department of Psychosomatics and Psychotherapy, St Marien Hospital, Bonn, Germany \\ ${ }^{2}$ Department of Child and Adolescent Psychiatry, University of Cologne, Köln, Germany \\ ${ }^{3}$ Department of General and Visceral Surgery, University of Cologne, Köln, Germany \\ Email: michael.langenbach@marien-hospital-bonn.de
}

Received September 11, 2012; revised October 17, 2012; accepted October 27, 2012

\begin{abstract}
Little is known about long-term quality of life of kidney donors. We studied subjective experiences of donors before and two years after kidney donation using in-depth interviews of eleven subjects. Interviews were audiotaped, transcribed, and analyzed by qualitative content analysis (grounded theory). Resulting categories of this process were grouped in order to construct ideal types of subjective experiences after kidney donation. Of our donors, $64 \%$ were female, mean age was 40.4 years. Donors reported that they had had no medical problems after donation. Most displayed psychological problems, e.g. difficulties adjusting to the new situation, hypochondriacal complaints, and fear of rejection of the recipient's kidney. Psychological complaints were particularly troublesome in case of complications of the recipient. All donors wished extended counselling after kidney donation. Identifying problems of kidney donors may be easier when doctors are trained in typical experiences. This may also guide the tailoring of individual psychological interventions.
\end{abstract}

Keywords: Living Donor; Qualitative Study; Quality of Life; Renal Transplantation; Subjective Experiences

\section{Introduction}

Kidney transplantation is the treatment of choice for selected patients with end-stage renal disease (ESRD). Due to continuing organ shortage, living kidney donation (LKD) has gained increasing importance in Germany in recent years. It has been established that quality of life (QoL) is an important outcome to quantify the success of transplantation for recipients in the long term $[1,2]$. Subjective wellbeing of kidney recipients has been studied much more often than that of donors. The preservation of QoL of living kidney donors is, however, paramount. Most studies on quality of life (QoL) of donors report good global QoL within the first years after kidney donation but also some mental and physical symptoms and relationship problems between donor and recipient [3-8; Table 1].

These studies cannot sufficiently explain which donors have psychological problems for what reasons, as group statistical approaches cannot account for individual variations of the meaning of kidney donation [9]. QoL and the sense donors make out of their donation is a uniquely personal perception and depends on numerous personal circumstances [9-11].

Quality of life is a complex, multifaceted construct that requires multiple approaches from different theoretical angles. It has been commonly accepted by researchers

Table 1. Studies of QoL after LKD.

\begin{tabular}{|c|c|c|c|c|c|c|}
\hline Author & Westlie et al. 1993 & Johnson et al. 1999 & $\begin{array}{l}\text { de Graaf Olson et al. } \\
2001\end{array}$ & $\begin{array}{l}\text { Isotani et al. } \\
\quad 2002\end{array}$ & $\begin{array}{l}\text { Giessing et al. } \\
2004\end{array}$ & $\begin{array}{l}\text { Shresta et al. } \\
2008\end{array}$ \\
\hline Sample & 494 & 979 & 118 & 104 & 118 & 66 \\
\hline $\begin{array}{l}\text { QoL (SF-36) vs. } \\
\text { gen.pop. }\end{array}$ & better & better & better & similar & similar - better & similar \\
\hline $\begin{array}{c}\text { QoL } \\
\text { (SF-36) worse if }\end{array}$ & $\begin{array}{l}\text { transplant loss/death of } \\
\text { recipient }\end{array}$ & $\begin{array}{l}\text { distant relationship/death of } \\
\text { recipient }\end{array}$ & distant relationship & transplant loss & $\begin{array}{c}\text { age } 31-40 / \\
\text { complications } \\
\text { donor or recipient }\end{array}$ & comorbidities \\
\hline Comments & & $\begin{array}{l}\text { More stress: female donors/ } \\
\text { perioperative complications }\end{array}$ & $\begin{array}{l}50 \% \text { without further } \\
\text { care }\end{array}$ & $\begin{array}{c}16 \% \text { negative } \\
\text { financial sequelae }\end{array}$ & & \\
\hline
\end{tabular}


on QoL that subjective views of studied subjects are very important for their sense of wellbeing and health $[12,13]$. This is true, in particular, for a highly complex medical field such as transplantation [14]. We therefore employed qualitative measures in order to capture kidney donors' subjective meanings and reconstruction of their subjective sense of kidney donation two to three years after LKD. The study was conducted with the understanding and the consent of the human subjects. The responsible Ethical Committee approved the study.

\section{Methods}

We interviewed fifteen pairs of recipients and donors before LKD and asked them about expectations, fears and hopes about LKD. We approached them again two years after LKD by letter. Eleven pairs agreed to take part in our investigation. Each of the participants gave written consent to be interviewed. We performed semistructured interviews which were audio-taped and transcribed according to accepted standards [15].

We designed the interviews as "narrative interviews": LK donors were asked open questions and encouraged to follow their own "narrative flow" in order to encompass also preconscious and unconscious thoughts and phantasies. We recurred to our interview guidelines (a series of predesigned themes and questions to present complaints and general condition, the views on the transplantation process and its turn out, the views on one's own body and its alterations by LKD, health behaviour, social support, etc.) only in case we felt these themes were not touched upon by the donors themselves.

We employed a qualitative content analysis using Grounded Theory [16] and grouped the resulting categories into ideal types [17] of trajectories after LKD. In a first step, the interviews (often more than 25 pages) were condensed to non-redundant, composite texts.

In a next step, we constructed more abstract categories from these texts (inductive method, according to [16]). We performed further condensations of these categories in group discussions, in order to work out subjective perspectives and evaluations of donors regarding the LKD process. In a final step, we constructed three ideal types of trajectories after LKD which seemed to us most apt to describe the different prevailing emotional states of donors with regard to the LKD.

\section{Results}

The eleven donors (seven female) had a mean age of 40.36 years (female: 43.43 yrs/male: 35 yrs). The four pairs of donors and recipients of LKD who did not agree to be interviewed declared that they felt well and had no major problems. Relationships between donors and recipients are displayed in Table 2.

An overview of donors' expectations and experiences before and after LKD is given in Table 3.

At the time before LKD, donors declared that they wished to donate their kidney because they felt sympathy with the complaints of the recipient and wanted to help to improve the recipient's QoL. A majority of donors expressed the wish to improve the relationship to the recipient or to the family, and expected to ameliorate also their own QoL.

After the LKD, all donors reported that they had had no medical problems. Most donors experienced the operation as more painful than they had expected. One pair had experienced kidney rejection, and the recipient had to undergo re-transplantation. This did not affect the relationship between donor and recipient. The donor declared

Table 2. Clinical data of donors studied.

\begin{tabular}{|c|c|c|c|c|}
\hline Donor & Recipient age/sex & Sex & Relationship donor to recipient & Years between transplantation and interview \\
\hline 1 & 40/ㅇ & $\hat{\sigma}$ & wife & 3.0 \\
\hline 2 & $41 / q$ & $\hat{0}$ & wife & 3.0 \\
\hline 3 & $71 /$ 早 & $\hat{0}$ & mother & 1.7 \\
\hline 4 & $44 / 9$ & q & sister & 2.0 \\
\hline 5 & $45 / 9$ & q & mother & 2.0 \\
\hline 6 & $29 / 9$ & q & daughter & 2.0 \\
\hline 7 & $34 / 9$ & q & friend & 2.3 \\
\hline 8 & $24 / \widehat{\jmath}$ & $\hat{0}$ & son & 2.5 \\
\hline 9 & $44 / \widehat{\jmath}$ & 우 & husband & 2.0 \\
\hline 10 & $37 / \widehat{O}$ & q & son & 3.1 \\
\hline 11 & $35 / \widehat{\partial}$ & 우 & partner & 2.1 \\
\hline
\end{tabular}


Table 3. Donors' expectations and feelings before Tx and experience two years after Tx.

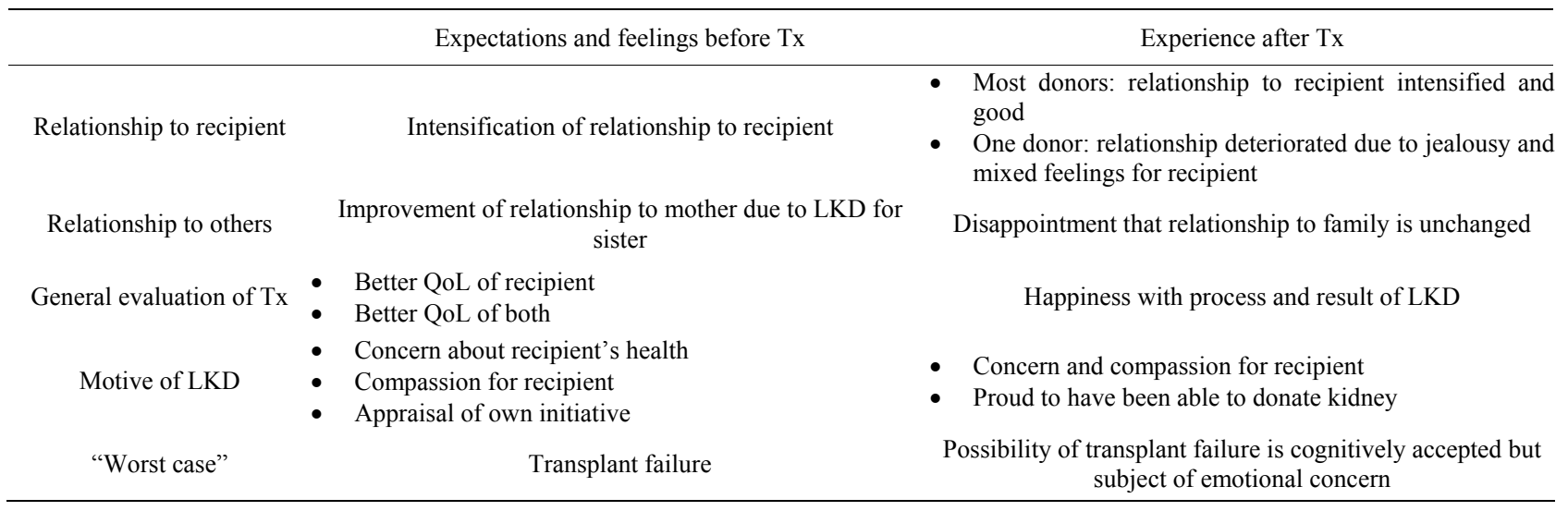

that he did not regret kidney donation and would do so again, although he felt more aware of possible complications and transplant loss. Most donors reported some kind of psychological complaints, such as difficulties adjusting to the new situation, heightened awareness for their physical wellbeing, fear of rejection of the recipent's kidney, or expressed disappointment of their expectations before LKD. Social problems included adjustment disorders within families. Some donors felt that their subjective experience of donation interfered with the experience of the family. They had expected a rise within the family hierarchy which had been disappointed. One female donor had expected to gain more acceptance by her mother after doantion of her kidney to her sister but was disappointed after LKD that she felt her relationship to her mother was unchanged. One donor had had difficulties with life insurance companies which had refused an application of insurance after LKD. All donors expressed the feeling of being "forgotten" over the intervening years after initially treated as "sensational" (e.g. being interviewed by the press) and cared for by the transplantation team. They all wished to be acknowledged as benefactors.

The grouping of categories in order to construct ideal types of trajectories after LKD resulted in establishing three ideal types which describe the prevailing emotional state of donors with regard to the LKD:

- Satisfaction and happy feelings of having been able to help to transform recipients' life to a state of improved QoL.

- Prevailing feelings of fear and concern about own health status with tendencies to regression into heightened self-observation and hypochondriacal preoccupations.

- Intense but ambivalent relationship to the recipient, e. g. mixed feelings of generosity (granting the recipient his new options) and envy (enviously observing the new potentials of the recipient).

Most of the interviewed donors were grouped as mixed types with a majority fulfilling criteria of type 1 (satisfaction and happy feelings).

\section{Discussion}

Our result that most of the donors are satisfied with the process of LKD and happy with their decision to donate are in keeping with results from other studies. Kärrfelt et al. [18] found a profound happiness with donation in parents of infant recipients. Fehrman-Ekholm [19,20] reported a similar satisfaction between adult donors and recipients. There have been reports that QoL of kidney donors is not experienced as limited, compared to healthy controls, but sometimes as even better in some dimensions $[4,20]$. Most donors would donate their kidney again $[18,19]$.

There are some specific psychological problems of the donors after LKD such as familial conflicts or heightened awareness for their physical wellbeing. Some of the problems had to do with disappointed expectations, e.g. when wishes for an intensification of relationship with the recipient or within the family were not met. We were able to identify three distinct ideal types of trajectories after LKD. Each of these ideal types may display specific problems in the course of rehabilitation and later on. In particular, patients with prevailing type two ideal type pattern with hypochondriacal tendencies may present themselves often for suspected medical problems and may need special psychological support. Relating an individual patient to one of the ideal types may help identify specific problems and guide the tailoring of individual psychological interventions.

\section{Conclusions}

As most of the studied kidney donors displayed psychological rather than medical problems, e.g. difficulties adjusting to the new situation, hypochondriacal complaints, and fear of rejection of the recipient's kidney, doctors should pay increased attention to the psycho- 
logical wellbeing of donors. Doctors dealing with kidney donors and recipients should be trained in typical psychological experiences of donors and recipients of LKD. They should be prepared to recognize and assure donors with prevailing hypochondriacal tendencies who may present themselves often for suspected medical problems.

It is remarkable that all donors of our study felt "forgotten" and wished for extended counselling after kidney donation. It should be kept in mind whether extended after-care for donors could help prevent the development of possible mental disorders, such as posttraumatic disorder or hypochondriacal tendencies.

Psychological complaints were particularly troublesome in case of complications of the recipient. In case of such more troublesome complaints, referral to specialised psychosomatic care should be considered.

Specialists in psychosomatic care should be aware of specific subjective patterns of coping with kidney donation and tailor their psychological interventions according to individual problems of donors.

\section{REFERENCES}

[1] M. Neipp, B. Karavul, S. Jackobs, et al., "Quality of Life in Adult Transplant Recipients More than 15 Years after Kidney Transplantation," Transplantation, Vol. 81, No. 12, 2006, pp. 1640-1644. doi:10.1097/01.tp.0000226070.74443.fb

[2] K. Griva, J. Stygall, J. H. Ng, et al., "Prospective Changes in Health-Related Quality of Life and Emotional Outcomes in Kidney Transplantation over 6 Years," Journal of Transplantation, Vol. 2011, Article ID: 671571, 12 p. doi: $10.1155 / 2011 / 671571$

[3] L. Westlie, P. Fauchald, T. Talseth, A. Jakobsen and A. Flatmark, "Quality of Life in Norwegian Kidney Donors," Nephrology, Dialysis, Transplantation, Vol. 8, No. 10, 1993, pp. 1146-1150.

[4] E. M. Johnson, J. K. Anderson, C. Jacobs, et al., "LongTerm Follow-Up of Living Kidney Donors: Quality of Life after Donation," Transplantation, Vol. 67, No. 5, 1999, pp. 717-721. doi:10.1097/00007890-199903150-00013

[5] W. de Graaf Olson and A. Bogetti-Dumlao, "Living Donors' Perception of Their Quality of Health after Donation," Progress in Transplantation, Vol. 11, No. 2, 2001, pp. 108-115.

[6] S. Isotani, M. Fujisawa, Y. Ichikawa, et al., "Quality of Life of Living Kidney Donors: The Short-Form 36-Item Health Questionnaire Survey," Urology, Vol. 60, No. 4, 2002, pp. 588-592. doi:10.1016/S0090-4295(02)01865-4

[7] M. Giessing, S. Reuter, B. Schönberger, et al., "Quality of Life of Living Kidney Donors in Germany: A Survey with the Validated Short Form-36 and Giessen Subjective Complaints List-24 Questionnaires," Transplantation, Vol. 78, No. 6, 2004, pp. 864-872.

\section{doi:10.1097/01.TP.0000133307.00604.86}

[8] A. Shresta, A. Shresta, C. Vallance, et al., "Quality of Living Kidney Donors: A Single-Center Experience," Transplantation Proceedings, Vol. 40, No. 5, 2008, pp. 13751377. doi:10.1016/j.transproceed.2008.03.132

[9] M. A. Dew, "Quality-of-Life Studies: Organ Transplantation Research as an Exemplar of Past Progress and Future Directions," Journal of Psychosomatic Research, Vol. 44, No. 2, 1998, pp. 189-195.

[10] G. Greif-Higer, E. Wandel, G. P. R. Otto, P. R. Galle and M. E. Beutel, "Psychological Conflicts between Relatives during the Long-Term Course after Successful Living Organ Donation," Transplantation Proceedings, Vol. 40, No. 4, 2008, pp. 902-906. doi:10.1016/j.transproceed.2008.03.040

[11] J. Reimer, A. Rensing, C. Haasen, et al., "The Impact of Living-Related Kidney Transplantation on the Donor's Life," Transplantation, Vol. 81, No. 9, 2006, pp. 12681273. doi:10.1097/01.tp.0000210009.96816.db

[12] T. M. Gill and A. R. Feinstein, "A Critical Appraisal of the Quality of Quality-of-Life Measurements," Journal of the American Medical Association, Vol. 272, No. 8, 1994, pp. 619-626. doi:10.1001/jama.1994.03520080061045

[13] E. Diener and E. Suh, "Measuring Quality of Life: Economic, Social, and Subjective Indicators," Social Indicators Research, Vol. 40, No. 1-2, 1997, pp. 189-216. doi:10.1023/A:1006859511756

[14] D. Joralemon and K. M. Fujinaga, "Studying the Quality of Life after Organ Transplantation: Research Problems and Solutions," Social Sciences \& Medicine, Vol. 44, No. 9, 1997, pp. 1259-1269. doi:10.1016/S0277-9536(96)00256-0

[15] E. Mergenthaler and C. Stinson, "Psychotherapy Transcription Standards," Psychotherapy Research, Vol. 2, No. 2, 1992, pp. 125-142. doi:10.1080/10503309212331332904

[16] A. Strauss and J. Corbin, "Basics of Qualitative Research," Sage, Thousand Oaks, 1990.

[17] M. Weber, "Die 'Objektivität' Sozialwissenschaftlicher und Sozialpolitischer Erkenntnis,” In: J. Winckelmann, Ed., Gesammelte Schriften zur Wissenschaftslehre, 3rd Edition, Mohr, Tübingen, 1968, pp. 146-214.

[18] H. M. Kärrfelt, U. B. Berg, F. I. Lindblad and G. E. Tydén, “To Be or Not to Be a Living Donor: Questionnaire to Parents of Children Who Have Undergone Renal Transplantation," Transplantation, Vol. 65, No. 7, 1998, pp. 915-918.

[19] I. Fehrman-Ekholm, "Living Donor Kidney Transplantation," Transplantation Proceedings, Vol. 38, No. 8, 2006, pp. 2637-2641. doi:10.1016/j.transproceed.2006.07.027

[20] I. Fehrman-Ekholm, B. Brink, C. Ericsson, et al., "Kidney Donors Don't Regret: Follow-Up of 370 Donors in Stockholm Since 1964," Transplantation, Vol. 69, No. 10, 2000, pp. 2067-2071. doi:10.1097/00007890-200005270-00016. 